\title{
COLLEGE STUDENTS' PREFERENCE AND SATISFACTION OF SCHOOL WECHAT OFFICIAL ACCOUNTS
}

\author{
Zeyu Zeng and Zhiqiang Luan \\ International College Beijing \\ China Agricultural University, Beijing, 100083, P.R. China
}

\begin{abstract}
The article investigates on college students' preference and satisfaction of School WeChat Official Accounts (SWOA). To identify the importance of the research, the article illustrates the rapid development of WeChat and SWOA, and the significance for college departments. To gather information about college students' preference and satisfaction, the author uses questionnaires as the primary approach. To analyze data, the author adopts Statistical Product and Service Solutions (SPSS) as the analytical tool. Finally, depending on research, further suggestion is that providing useful information and simple function, and applying various expressions is key to run an appealing SWOA and attract more college students to follow it.
\end{abstract}

\section{KEYWORDS}

WeChat Official Accounts, College Students, New Media Technology, Social Software

\section{INTRODUCTION}

The article's topic is about college students' preference and satisfaction of School WeChat Official Public Accounts (SWOA). The research is attractive for college departments because of the popularity of SWOA and the rising requirement to develop connections with college students. Since WeChat becomes a popular social platform in Chinese society, WeChat Official Accounts (WOA) grow to be the basic platform for Chinese people to receive and deliver media messages, let alone college students. For college departments, they eagerly want to build efficient channels to connect with college students. Therefore, it is meaningful to know their preference and satisfaction of SWOA. Then, college departments can do better jobs on operating SWOA and build more effective connections with college students.

\section{LITERATURE REVIEW}

\subsection{Background of WeChat}

With the rapid development of Internet technology, social media has become an irreplaceable tool in people's daily lives and hugely change styles of communication. In the unstoppable tendency, WeChat, created by Tencent, successfully grabs the chance and gains increasing popularity in Chinese society. WeChat as a developed digital platform that integrates "social networking communication, mobile payments, e-commerce, public services, and an application programming interface for other apps" (Wang, Zhang, \& Zeng, 2019, pp.244). During the 2018 Spring Festival, the number of consolidated monthly users of WeChat has exceeded one billion, which "implies basic full coverage of age-appropriate population as the Chinese population aged from 15 to 64 approximately number one billion" (Shi, Wang, Yao, Duan, \& Ma, 2018, pp.12). Therefore, WeChat has already become the hottest social media in China for people to communicate with each other and receive daily information. 


\subsection{Background of WeChat Official Accounts}

WeChat Public Platform, first released in 2012, is one of functional part within WeChat, which is consist of numerous active WeChat Official Accounts (WOA) to "offers a low-cost efficient communication tool for individual providers of we-media information services" (Shi et al., 2018, pp.13). According to the article from Qiao, Xie and Li, WOA contain three advantages, which are authenticity of user, controllability of fan, and authenticity of Internet, which make WOA outstanding and appealing (2019). WeChat contains over billion users within over 200 countries and over languages and possesses more than 20 million WOA (Li, Huang, \& He, 2018). According to the recent report released by company QuestMobile, nearly half of users follow 10 to $20 \mathrm{WOA}$, and about a quarter of users follow more than $20 \mathrm{WOA}$. About time spending, about half of users spend 10 to 30 minutes, and 22 percent of users spend 30 to 60 minutes every day (Thomas, 2019). In short, WeChat Public Platform has grown into the biggest platform for Chinese people to obtain daily messages at the same time. Because the traditional communication tools gradually become outdated and unpopular, school-run WOA, which is called SWOA, become more and more significant in Chinese universities. Therefore, it is reasonable to conclude that SWOA is an important medium for school departments to build and maintain a connection with Chinese college students.

\subsection{Satisfaction Factors Model about WeChat Official Accounts}

Traditional models include the technology acceptance model and the American Customer Satisfaction Index. In the research, the author chooses the satisfaction factors model created by Li, Long, and Wen (Figure 1). It absorbs advantages from traditional models and makes changes to suit features of WOA (Li, Long, \& Wen, 2016).

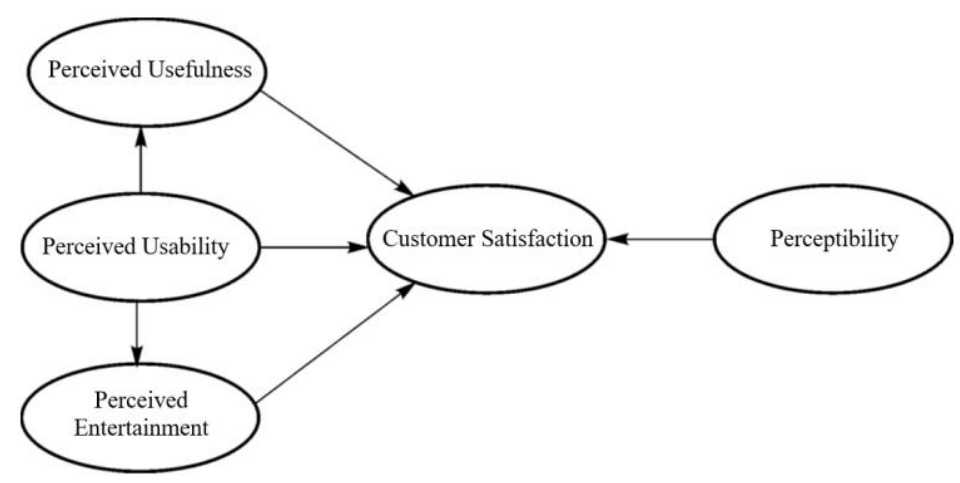

Figure 1. Satisfaction factors model about WeChat Official Public Accounts

\section{METHODOLOGY}

\subsection{Research Method}

To collect enough data, the author chooses to survey by digital questionnaire as research approach. In the question sheets, the author designs 16 multiple choices, which can be divided into three parts. The first part is planned to understand chosen college students' basic information. The second part is designed to understand the relationship between college students' learning behaviour and SWOA. The third part is going to ask their preference and satisfaction depends on different areas of SWOA. At the end of the questionnaires process, the author finally gets 490 valid copies of answers. 


\subsection{Analysis Approaches}

To analyse the collected data, the author chooses to use Statistical Product and Service Solutions (SPSS) as the analytical tool. In practice, the author uses bivariate correlation analysis and multiple linear regression analysis to detect relationships and insights among the questionnaires. Bivariate correlation analysis is used to find an empirical relationship between each two variables (Babbie, 2010). Multiple linear regression analysis is applied to find a symbolic outcome by adding a mixture of predictors (Pandis, 2016), which can also be used to find the relationship between one dependent variable and other independent variables.

\section{RESULTS}

\subsection{Bivariate Correlation Analysis}

The result of bivariate correlation analysis shows that except the question about gender, other questions have different degrees of relationship with the satisfaction and preference on School WeChat Public Accounts (Table 1). Questions include "SWOA accounts is convenient for me to obtain useful information", "SWOA's functions are simple to understand and practice", "SWOA's recreational content can bring me fun", "SWOA contain various information", "SWOA contain various expression", and "SWOA' content is useful and available for me" highly related to their preference and satisfaction. However, since all questions are related to preference and satisfaction, it is hard to discover concrete conclusions and findings. Then, the author uses multiple linear regression analysis to find further relationships among these different questions.

Table 1. Bivariate correlation analysis

\begin{tabular}{lc}
\hline & $\begin{array}{c}\text { I am satisfied with school } \\
\text { WeChat official public } \\
\text { accounts/ Pearson Correlation }\end{array}$ \\
\hline What is your gender? & -0.075 \\
What is your grade? & 0.163 \\
Do you hope that SWOA recommend you classmates depends on your personal & 0.365 \\
$\quad$ information? & 0.392 \\
Do you think it is good for students' enthusiasm by developing group study in SWOA? & 0.428 \\
Do you think it is good for students' enthusiasm by developing online teaching in SWOA & 0.378 \\
Do you think it is beneficial for students' enthusiasm by posting information and & \\
$\quad$ developing mutual answering by SWOA? & 0.391 \\
Do you think it is more convenient to submit class assignments and initiate activities by & \\
$\quad$ SWOA? & 0.234 \\
Do you hope that teachers post scores by SWOA? & 0.341 \\
Do you want to know information about activities by SWOA? & 0.525 \\
SWOA is easy for me to obtain useful information. & 0.582 \\
SWOA's functions are simple to understand and practice. & 0.562 \\
SWOA's recreational content can bring me fun. & 0.624 \\
SWOA contain various information. & 0.627 \\
SWOA contain various expression. & 0.703 \\
SWOA' content is useful and available for me. & \\
\hline
\end{tabular}




\subsection{Multiple Linear Regression Analysis}

\subsubsection{Model Summary}

The outcome of the model summary shows that the $S$ square is 0.617 (Table 2), which means that all 15 questions as independent variables can explain 61.7 percent of college students' preference and satisfaction of SWOA as the dependent variable.

Table 2. Model summary

\begin{tabular}{cc}
\hline $\mathrm{R}$ & $\mathrm{R}$ Square \\
\hline 0.785 & 0.617 \\
\hline
\end{tabular}

\subsubsection{Anova}

The outcome of Anova shows that $\mathrm{F}=50.847$, and $\mathrm{p}=0.00<0.05$ (Table 3), which means that at least 1 question as the independent variables influences college students' preference and satisfaction of SWOA as the dependent variable.

Table 3. Anova

\begin{tabular}{ccc}
\hline Model & F & Sig \\
\hline Regression Residual Total & 50.847 & 0.00 \\
\hline
\end{tabular}

\subsubsection{Coefficient}

Table 4. Coefficient

\begin{tabular}{llll}
\hline & $\mathrm{B}$ & $\mathrm{t}$ & \multicolumn{1}{l}{ Sig } \\
\hline What is your gender? & -0.061 & -1.158 & 0.248 \\
What is your grade? & 0.050 & 2.062 & 0.04 \\
Do you hope that SWOA recommend you classmates depends on your personal information? & 0.034 & 1.169 & 0.243 \\
Do you think it is good for students' enthusiasm by developing group study in SWOA? & -0.003 & -0.087 & 0.931 \\
Do you think it is good for students' enthusiasm by developing online teaching in SWOA? & 0.057 & 1.613 & 0.107 \\
Do you think it is beneficial for students' enthusiasm by posting information and developing & -0.032 & -0.910 & 0.363 \\
$\quad$ & & \\
$\quad$ mutual answering by SWOA? & 0.073 & 2.682 & 0.008 \\
Do you think it is more convenient to submit class assignments and initiate activities by & & \\
$\quad$ SWOA? & -0.021 & -0.909 & 0.364 \\
Do you hope that teachers post scores by SWOA? & 0.031 & 0.915 & 0.361 \\
Do you want to know information about activities by SWOA? & 0.068 & 1.646 & 0.100 \\
SWOA is easy for me to obtain useful information. & 0.111 & 2.564 & 0.011 \\
SWOA's functions are simple to understand and practice. & 0.042 & 1.203 & 0.230 \\
SWOA's recreational content can bring me fun. & 0.159 & 3.954 & 0.000 \\
SWOA contain various information. & 0.109 & 2.528 & 0.012 \\
SWOA contain various expression. & 0.320 & 7.670 & 0.000 \\
\hline SWOA' content is useful and available for me. & &
\end{tabular}

The outcome is listed as above (Table 4). The result proves that there are five questions have remarkable influences on college students' preference and satisfaction of SWOA. They are "What is your grade," "Do you think it is more convenient to submit class assignments and initiate activities by SWOA," "SWOA's functions are simple to understand and practice," "SWOA contain various information," and "SWOA contain various expression." The value of regression coefficient about "What is your grade" is $0.05(\mathrm{t}=23062$, $\mathrm{p}=0.04<0.05$ ). The value of regression coefficient about "Do you think it is more convenient to submit class assignments and initiate activities by SWOA" is $0.073(\mathrm{t}=2.682, \mathrm{p}=0.008<0.01)$. The value of regression coefficient about "SWOA's functions are simple to understand and practice" is $0.111(\mathrm{t}=2.564,0.011<0.05)$. 
The value of regression coefficient about "SWOA contain various information" is $0.159(\mathrm{t}=3.954$, $\mathrm{p}=0.000<0.01)$. The value of regression coefficient about "SWOA contain various expression" is 0.109 $(\mathrm{t}=2.528, \mathrm{p}=0.012<0.05)$.

\section{DISCUSSION}

The results of bivariate correlation analysis and multiple linear regression analysis provide valuable insights. In bivariate correlation analysis, the result means that preference and satisfaction of SWOA are influences by comprehensive factors, which means that if school departments want to manage SWOA successfully, they should make efforts on various areas to achieve integral progress.

However, some factors are relatively detrimental and decisive, and multiple linear regression analysis gives the answer. The outcome means that SWOA is a content-oriented platform. The question "What is your grade" means that college students from different grades have various types of requirements about SWOA. The question "SWOA's functions are simple to understand and practice" means that whether it is easy to obtain information from SWOA is essential. The question "SWOA contain various expression" means that various expression of content is attractive for college students. The questions "SWOA contain various information" directly shows the requirement for college students to obtain useful information.

Therefore, SWOA is a content-oriented platform for college students to obtain messages. For school departments, it is crucial to provide useful and valuable information to meet the requirement of college students.

\section{CONCLUSION}

SWOA, acting as an essential platform for school departments to build and maintain connection with students. Therefore, it is valuable to know how to attract college students' eyes and meet their requirements. After receiving 490 copies of answers, and using bivariate correlation analysis and multiple linear regression analysis with the help of SPSS, the author finds worthy insights.

By using bivariate correlation analysis, the author knows that except gender as an independent variable, other 15 questions are influential on SWOA. By using multiple linear regression analysis, I get the result that "What is your grade", "Do you think it is more convenient to submit class assignments and initiate activities by SWOA", "SWOA's functions are simple to understand and practice", "SWOA contain various information", and "SWOA contain various expression", as five independent variables, have remarkable influences.

Therefore, it means that useful information is an essential requirement for college students. If school departments want to attract more college students to follow their SWOA, they should pay more attention to providing useful information, making functions more straightforward, and varying expression of daily news.

\section{REFERENCES}

Babbie, E. R. (2010). The practice of social research (12th ed.). Belmont, Calif: Wadsworth Cengage.

Li, X. Long, Q., \& Wen, S. (2016). Influencing factors on students' satisfaction of WeChat Public Platforms of Universities - An empirical study based on SEM. 18(4), 6-12.

Li, K., Huang, X., \& He, X. (2018). Research on the construction of the attractiveness of universities WeChat Public Accounts - Taking Communist Youth League Public Platform of Guangxi University as an example. 2018 International Joint Conference on Information, Media and Engineering (ICIME). 183-186. doi: 10.1109/icime.2018.00045

Pandis, N. (2016). Multiple linear regression analysis. American Journal of Orthodontics and Dentofacial Orthopedics, 149(4), 581-581. doi:10.1016/j.ajodo.2016.01.012 
Qiao, P., Xie, X., \& Li, D. (2019). Thoughts on the development of meteorological wechat public platform. Meteorological and Environmental Research, 10(4), 42-44. doi:10.19547/j.issn2152-3940.2019.04.011

Shi, Z., Wang, Y., Yao, X., Duan, Y., \& Ma, M., (2018). Build an Innovative Community of Shared Ecosystem and Foster New Drives of Economic Growth. China Academy of Information and Communications Technology Industry and Planning Research $\quad$ Institute. $\quad$ Retrieved from http://www.caict.ac.cn/kxyj/qwfb/ztbg/201805/t20180503_168382.htm

Thomas G, 2019. WeChat Official Account Report 2019 reveals importance of cross-promotion \& social shopping. Retrieved from https://walkthechat.com/wechat-official-account-report-2019-reveals-importance-of-cross-promotionsocial-shopping/.

Wang, G., Zhang, W., \& Zeng, R. (2019). WeChat use intensity and social support: The moderating effect of motivators for WeChat use. Computers in Human Behavior, 91, 244-251. doi:10.1016/j.chb.2018.10.010 